\title{
Inovação na perspectiva dos inovadores: a experiência do Programa Gestão Pública e Cidadania
}

\section{Peter Spink*}

\section{Resumo}

Criado em 1996 por iniciativa da Fundação Ford e a Fundação Getulio Vargas com o apoio do BNDES, o Programa Gestão Pública e Cidadania vem trabalhando de maneira ativa na identificação e disseminação de iniciativas inovadoras dos governos subnacionais brasileiros que melhoram a qualidade dos serviços públicos e contribuem para construção da cidadania. Nos oito anos do programa, mais de 6,200 experiências foram identificadas oriundas dos estados, municípios e governos próprios dos povos indígenas. Neste texto a temática da inovação é discutida a partir das respostas dos programas, projetos e atividades identificadas a esta questão, trazendo uma nova ótica a discussão entre inovação e "melhores práticas".

Palavras-chave: inovações no setor público, definições práticas, governos locais, Brasil

\begin{abstract}
The Public Management and Citizenship Program was set up in 1996 as a joint initiative of the Ford Foundation and the Getulio Vargas Foundation with the added support of the BNDES. Its objective is to identify and disseminate information about innovative practices in sub national governments in Brazil that improve the quality of public services and produce a positive impact on the construction of citizenship. In the program's eight years to date, some 6,200 different experiences have been identified coming from state and local governments and the governments of the indigenous peoples. In this paper the theme of innovation is discussed using as a basis the answers of the different programs, projects activities to the same question. The result offers a new perspective of the discussion of the differences between innovations and "best practices".
\end{abstract}

Keywords: public sector inovations, pratical definitions, local government, Brazil

Criado em 1996, por iniciativa da Fundação Ford e da Fundação Getulio Vargas (FGV), com o apoio do BNDES, o Programa Gestão Pública e Cidadania vem trabalhando de maneira ativa na identificação e disseminação de iniciativas inovadoras dos governos subnacionais brasileiros que melhoram a qualidade dos serviços públicos e contribuem para construção da cidadania. Nos oito anos do programa, algo em torno de 6.000 experiências foram identificadas e mais de 200 estudos de caso publicados, além de bancos de dados, vídeos e outras formas de disseminação, incluindo o apoio a programas de emissoras de rádio comunitárias.

Seus métodos de identificação e disseminação são relativamente novos no mundo acadêmico. Buscando criar um mecanismo capaz de ir além das inovações já conhecidas e identificar os estados e municípios de maior destaque no cenário técnico e político, o programa optou por utilizar um prêmio anual, aberto a todas as "jurisdições subnacionais" (estados, municípios e os governos próprios dos povos indígenas) e com critérios flexíveis de inscrição. Essa abordagem inclusiva também se faz presente no processo de disseminação, onde todas as experiências enviadas ao Programa Gestão Pública e Cidadania são incluídas no banco de dados e recebem certificados de participação.

O processo de avaliação é feito em três etapas. Na primeira, são selecionados 100 programas, projetos ou atividades semifinalistas, a partir da informação fornecida na ficha de inscrição. Na segunda, após receber maiores detalhes dos programas semifinalistas, são selecionados 30 pré-finalistas, que recebem a visita de um técnico ou pesquisador para verificar in loco a iniciativa. Na etapa final, 20 finalistas são selecionados para compor o conjunto de experiências exemplares do ano, apresentadas num evento de confraternização e aprendizagem onde cinco destaques são indicados. Ao longo do processo, pesquisadores, técnicos, professores, gestores públicos e ativistas participam do processo de avaliação e discussão; debatendo a importância de cada iniciativa.

* Professor Títular FGV - EAESP. Coordenador do Centro de Administração Pública e Governo. PhD em Psicologia Organizacional, Birkbeck College, Universidade de Londres. E-mail: spink@ fgvsp.br. 
É inevitável que "inovação" seja um dos temas mais presentes nessas discussões. Afinal, o que é uma inovação? Por que uma atividade deve ser considerada mais inovadora do que outra, levando-se em conta, por exemplo, o contraste entre uma atuação local num município pequeno e um programa abrangente de uma área metropolitana? Nas informações circuladas na ficha de inscrição, a resposta a essa questão é deixada em aberto. Fora da obrigação de ter pelo menos um ano de implantação efetiva e de ser coordenado por uma organização pública, os programas, projetos e atividades submetidos devem demonstrar resultados claros de inovação em organização e/ou estratégias técnicas para resolver necessidades sociais e comunitárias que:

- representem mudança substantiva, qualitativamente ou quantitativamente em relação a práticas anteriores;

- permitem ou apontam as maneiras como a experiência pode ser repetida por outros e transferida a outras regiões e jurisdições;

- ampliam ou consolidam formas de acesso e diálogo entre a sociedade e suas agências públicas;

- utilizam recursos de maneira responsável e estimulam práticas autônomas que podem vir a ser autosustentadas.

\section{0 que é inovação}

O sentido amplo da palavra inovação é o de "tornar novo", "renovar", "introduzir novidade" ou "fazer algo como não era feito antes". Na língua inglesa, os pesquisadores do Dicionário Oxford encontraram, em 1597, "fazendo mudanças em algo estabelecido"; mais tarde, "introduzir novidade"; e em 1818, "renovar". A importância da citação de 1597 é demonstrar que ao contrário do que muitos imaginem, a noção de inovação não é uma característica exclusiva da modernidade. "Alterar aquilo que é estabelecido" é um conceito social poderoso que contribui para a noção de contradição e processo histórico. Aliás, dado que os relatos históricos disponíveis se caracterizam não pela permanência dos modelos e práticas institucionais, mas pela sua mudança, pode-se deduzir que alguma noção de "introduzir novidade" é parte central dos diversos caminhos da humanidade desde muito tempo atrás.

Ao mesmo tempo, há de se reconhecer que a mesma modernidade que transferiu o sentido de "revolução" da arena da física e da mecânica para a arena política e cultural é também a modernidade cuja busca pela melhoria estimulou a curiosidade, elevando a humanidade a novos patamares técnicos e sociais como nunca visto antes. Se "inovar" já existia, parece que na modernidade chegou a ocupar o centro das atenções até o ponto de ser o referencial para o correto, numa sutil inversão de valores em relação à conservação e à tradição, valorizando, por exemplo o "novo" em relação ao "obsoleto".

Se, como parece, "tornar novo" e "introduzir novidade" é um processo humano e social de longa data, segue com propriedade a pergunta: por que discutir "o que é inovação"? Afinal, em diversas línguas, o sentido da palavra não parece problemático, pertencendo ao senso comum, ao cotidiano. Nesse sentido, uma resposta pode ser dada a partir da similaridade e da proximidade com a noção de mudança e de uma outra pergunta: "por que resistir à mudança"? Ou seja, da mesma maneira que as sociedades contemporâneas, em grande parte democráticas e abertas, resultam da luta de pessoas por mudanças, também são resultado e produto daquelas que, de forma sábia e heróica, entendiam a importância de resistir a outras mudanças. Mudança nunca é, a priori, boa. Há mudanças vistas coletivamente como positivas, mas também há mudanças vistas como negativas. A inovação segue o mesmo caminho. A bomba atômica e as sementes geneticamente modificadas - para escolher duas - são, cada uma de sua maneira, inovações. Mas nem todas serão aplaudidas de maneira universal. O resultado é um debate moral, uma discussão sobre como a vida deve ser vivida.

Vista por essa ótica, a relação do novo com o existente é e sempre será contraditória, e as consequiências desse processo sempre serão abertas às diferentes interpretações. O empenho social, entendido como responsabilidade coletiva, exige abertura para o debate e a democratização extensa das opções, alternativas e conseqüências, e de avaliação (SPINK, 2001).

Há, sem dúvida, outros caminhos. Um, é o de adotar uma postura schumpeteriana, argumentando que novas formas evolvem a destruição criativa - resultado da competitividade -, assumindo uma visão evolucionista, que é a de que o novo será sempre mais adaptativo do que o velho. Um outro caminho é o de entregar a discus- 
são à ciência, através de regras de cálculo, de argumentação e da especificação dos parâmetros daquilo que é bom e útil. No terreno dos governos subnacionais e das políticas públicas, esta é a abordagem frequientemente adotada nos programas de melhores práticas, onde certos programas e práticas são identificados como exemplos a serem seguidos. Em ambos os casos, a questão da inovação é resolvida externamente, a partir da definição dos parâmetros de sucesso.

A opção do Programa Gestão Pública e Cidadania foi pelo debate aberto. Os critérios adotados buscam incluir e não excluir, cabendo indagar se de fato, houve mudança. Outras podem utilizar a experiência nas suas áreas ou lugares? O programa tem impacto na construção prática da cidadania? Há possibilidade de continuidade? Por sua vez, o programa assume que se as pessoas envolvidas na atividade consideram seu trabalho como inovador, de alguma maneira, ele será aceito e incluído no banco de dados e no processo de seleção. Se há uma ênfase, esta é dada no nome do programa, demonstrando preocupação com as ações públicas que têm impacto na construção da cidadania. O resto é resultado da discussão entre as pessoas que participam dos painéis de seleção e do uso de um mecanismo simples, onde cada programa e projeto é analisado por, pelo menos, dois grupos de pessoas diferentes ( 8 - 10, no total) em diferentes conjuntos de programas e projetos; trata-se, portanto, de pessoas diferentes e contextos diferentes. À medida que o processo de seleção avança para a fase dos semifinalistas e pré-finalistas, as informações disponíveis são maiores, ainda que o processo continue o mesmo até o final.

\section{Inovações ou melhores práticas}

Ao buscar um ponto de partida mais aberto para o Programa Gestão Pública e Cidadania, a intenção foi traçar uma distinção entre "compartilhar e disseminar inovações ou experiências que tenham algum êxito" e "melhores práticas" (SPINK 2000). Naquele primeiro momento, a idéia foi a de que "melhores práticas" tendiam a ser sempre apresentadas como soluções que "devem" ser seguidas porque são corretas e aprovadas. O debate e a discussão sobre por que, como, em que circunstâncias e quais os elementos-chave do processo parece ser deixado de lado. A tecnologia é veiculada como se fosse uma caixa preta: "faça assim, porque funciona".

Pode-se argumentar que um grau de pragmatismo é muito necessário no âmbito da ação social; entretanto há muita diferença entre a pergunta pragmática clássica "quanto precisamos saber?" e uma tendência de reduzir tudo ao mesmo nível da aspirina cuja eficácia em resolver dor-de-cabeça foi confirmada muito tempo antes de se saber como e porque teve esse efeito. Pragmaticamente, o mundo social é diferente da aspirina. Ele é, de alguma maneira, aberto para a análise; saberes são coletivos e a competência de compartilhá-los é assumida como algo dado (taken-for-granted) (GARFINKEL 1967; GEERTZ, 1983).

Ao tentar traçar essa distinção, o programa buscou reconhecer tanto a importância das possibilidades de ação presentes no dia-a-dia quanto a competência de atores sociais em elaborar idéias e estratégias que tornam os caminhos viáveis. De maneira similar, buscou-se evitar uma ênfase exagerada nos temas clássicos da bibliografia sobre "inovação", tais como "replicabilidade", escala e sustentabilidade. Não há dúvida que um programa, projeto ou atividade precisa oferecer a possibilidade de diálogo com ações similares e sobre as possibilidades de transferência dos conhecimentos presentes para outras áreas e questões, uma vez que compartilhar o que é aprendido é elemento constitutivo de uma vida coletiva e democrática. Mas ao enfatizar demais a "replicabilidade", a escala e a sustentabilidade, pode-se facilmente esquecer porque algo foi feito, suas razões endógenas. Afinal, por que as pessoas inovam? Para resolver problemas ou para ser replicado, ampliado e sustentado no longo prazo?

Em vez de assumir, abrir a discussão sobre "melhor" leva a uma segunda discussão sobre "melhor e para quem", discussão essa que ao tratar da interseção entre Estado e sociedade na contemporaneidade é longe de ser simples. Qual é, por exemplo, a cidadania ao qual o programa se refere? Será que é a cidadania liberal de Marshall (MARSHALL, 1967), dos direitos civis, políticos e sociais de um Estado do bem-estar, ou é a cidadania tumultuosa de uma sociedade onde a democracia política está longe de ser uma democracia social do dia-a-dia, onde para muitos, os direitos civis básicos ainda são um sonho (CARVALHO, 2001). Seria a cidadania coletiva dos povos indígenas? De novo, as opções oscilarão entre a especificação formal daquilo que é considerado bom ou correto e o reconhecimento de que, nas sociedades modernas, essas questões estão longe de serem resolvidas (CORNWALL, 2000; OLSSON e WOHLGEMUTH, 2003). 
Diante desse cenário conflituoso, talvez seja compreensível a opção metodológica das agências internacionais. Estas, visando produzir algo que seja aceito por todos os seus países-membros, acumulam critérios diferentes, de tal maneira que para se inscrever no programa de best practices da UNCHS-Habitat, é necessário compreender nove páginas de instruções em inglês; ou no da Unaids, em que é preciso responder a quase 40 perguntaschave. Esse reducionismo técnico talvez seja o preço a ser pago para permitir um mínimo de diálogo internacional. Entretanto, o resultado é, inevitavelmente, um processo de exclusão sutil, onde o acesso é restrito àqueles que conseguem se expressar na linguagem técnica e oficial. Nesse sentido, é conhecido que muitos atores sociais trabalham a partir de outras perspectivas de ação, usando as múltiplas linguagens do dia-a-dia (ESTEVA e PRAKASH, 1998). Numa situação onde o debate pode ser mais extenso e onde o confronto entre idéias é possível, há de se dar espaço para um outro caminho, o de assumir que, democraticamente, não há um a priori "melhor".

Sem grandes pretensões de ter sido claro nessa distinção entre as "inovações" e as "melhores práticas" - impossível porque as duas abordagens compartilham, em parte, a mesma fronteira das ações emergentes - o Programa Gestão Pública e Cidadania buscou se posicionar dentro dos processos diários da discussão de possibilidades e da troca de saberes, criando meios para apoiar e estimular os contatos entre agências públicas, movimentos sociais, grupos comunitários, políticos, acadêmicos e técnicos sobre as possibilidades de ação presentes nas experiências apresentadas. Os resultados têm sido os mais diversos, mas entre eles se destaca o reconhecimento da necessidade de assumir que "saberes" é plural e não singular, e que para muitas pessoas, os "saberes" não estão separados dos "fazeres". Para alguns, a teoria precede a ação; para outros, a teoria é a ação; e há aqueles para quem o agir é simplesmente o agir, uma responsabilidade social e moral é resolver problemas e melhorar a vida coletiva, e por conseqüência, a inovação está naquilo que acontece e não na idéia ou na teoria a partir da qual se pretendia agir.

Se o programa teve êxito nessa tentativa de manter aberta a discussão sobre inovação, é algo a ser debatido. Pode se identificar entre os mais de 6.000 inscritos no Programa Gestão Pública e Cidadania, desde o primeiro ciclo em 1996, uma grande variedade de estilos e de áreas de atuação, variedade essa que cresce ano após anos, trazendo constantemente novas questões, idéias e práticas (FARAH, 1999, 2001; FARAH e SPINK, 2003). Se o programa teria falhado nessa busca de abertura, é mais provável que o inverso acontecesse; que as inscrições fossem mais e mais similares em orientação, e que seu número diminuísse à medida que a presença de um formato padrão com parâmetros desejáveis, inevitavelmente, estimulasse a auto-rejeição. Mas há também um outro caminho disponível para arejar a questão da inovação: os próprios inscritos no ciclo anual de premiação. Afinal, o que é inovação para os inovadores?

\section{Um caminho de análise}

Há diversos caminhos possíveis para buscar uma resposta a essa questão, cada um com seus pontos positivos e negativos. Em primeiro lugar, na porta de entrada para o ciclo anual de premiação há a ficha de inscrição onde os programas, projetos e atividades buscam informar qual é o seu foco. As perguntas básicas, além de informações quanto à identificação, são: descreva como funciona o programa, projeto ou atividade e suas principais características; apresente os objetivos do programa, projeto e atividade; identifique o público beneficiário de seu programa, projeto ou atividade; o que você considera como o ponto mais inovador do programa, projeto ou atividade e por quê?; quais resultados ou indicadores (quantitativos ou qualitativos) mostram as melhorias produzidas pelo programa, projeto ou atividade?

Essa é a parte mais aberta do programa, onde há o maior número de inscritos e a maior variedade de atividades nas áreas mais diversas. Entretanto, também é o momento onde a clareza das respostas é mais vulnerável. É uma interação mediada pelo folheto de inscrição, e a tarefa principal para as pessoas que preparam a inscrição é transmitir uma boa descrição de problema e ação. A maior preocupação é, provavelmente, descrever bem o que estão fazendo, mais do que explicar "o que você considera como o ponto mais inovador de seu programa, projeto e atividade e por quê?"

Na segunda fase, onde os 100 semifinalistas recebem uma lista de 18 perguntas para responder, a situação é sutilmente diferente. Primeiro, sendo um grupo que é produto de um processo de seleção aberto, há uma maior 
probabilidade de se tratar de um programa, projeto ou atividade com um diferencial a mais em termos de sua contribuição potencial. Segundo, há, mesmo que por correspondência, um contato individual entre o Programa Gestão Pública e Cidadania e os responsáveis pela inscrição. Há um "parabéns" que é por si algo que estabelece uma relação de maior igualdade e é também um reconhecimento da competência de seu trabalho. Há, também, a possibilidade de usar mais espaço na resposta às perguntas, e há mais perguntas a serem respondidas, assim permitindo que os responsáveis entrem em maiores detalhes sobre as razões e as justificativas. As instruções dadas nessa fase são:

- responda às seguintes perguntas, lembrando que será com base em suas respostas que o seu programa, projeto ou atividade será avaliado. Portanto, seja preciso e objetivo, atendo-se ao que está sendo perguntado em cada questão;

- nenhuma resposta deverá ter mais do que uma página;

- no total, suas respostas não deverão somar mais do que sete páginas;

- lembre-se de que todos os 30 pré-finalistas receberão visitas de campo, durante as quais serão verificadas in loco as informações prestadas.

Entre as perguntas formuladas, temos: "em que aspectos seu programa, projeto ou atividade inovou em relação a práticas anteriores? Procure explicar bem em que consiste a inovação".

O ponto negativo, tal como na fase anterior, é o fato de que a resposta parte do responsável, formulada dentro de uma perspectiva de premiação. Não se sabe, por exemplo, quais outras versões sobre inovação estão circulando entre os membros das equipes de trabalho e entre os usuários dos serviços ou as comunidades do local. Para isso, um outro tipo de estudo seria necessário, detalhando mais um menor número de casos. Contudo, mesmo com essas restrições, as respostas dos semifinalistas oferecem a possibilidade de variedade. São oriundas de diferentes partes do país e de jurisdições de todos os tipos. Suas organizações variam de tamanho e nas tradições, e os responsáveis são de profissões as mais diversas. Sendo semifinalistas, estão, também disponível para análise, as fichas de inscrição original, o que permiti a comparação entre os argumentos apresentados.

A análise que será apresentada utilizou as fichas de inscrição e as respostas das questões complementares dos semifinalistas do ciclo 2001. Ao todo, foram 727 inscrições válidas neste ano, $84 \%$ municipais, $15 \%$ de organizações estaduais e 1\% das organizações próprias dos povos indígenas. Dos 100 semifinalistas, 72 eram do âmbito municipal, 23 estaduais, três indígenas e dois intermunicipais. Dos programas, projetos e atividades, 92 tiveram alguma forma de parceria ou aliança com outras organizações públicas ou da sociedade civil, e em 72 casos, a parceria era com ambos os tipos de organização. Por não enviarem as informações complementares, 11 programas e projetos foram excluídos: um indígena, dois de nível estadual e oito da área municipal. Trata-se de um fenômeno recorrente nos ciclos de premiação, podendo acontecer por várias razões, que vão desde a precariedade da atividade até o reconhecimento de que não se enquadra nas regras básicas (ser coordenado pelo setor público e ter um ano de efetiva implantação). Entretanto, os 89 programas, projetos e atividades resultantes representam bem a diversidade de áreas de atuação, as diferentes regiões geográficas do país e também as áreas urbanas e rurais. Incluem, naturalmente, os 30 programas pré-finalistas, bem como os destaques finais.

O método de análise consistiu de sete etapas:

1. a leitura de cada conjunto de respostas (ficha de inscrição e as 18 perguntas complementares) para contextualizar as respostas específicas às perguntas sobre inovação;

2. a justaposição das duas respostas (inscrição e questões complementares) para verificar diferenças;

3. a transcrição completa da parte da resposta voltada à temática do que é "inovação" em relação ao programa, ao projeto e à atividade;

4. a leitura flutuante de todas as respostas; repetida duas vezes;

5. a identificação dos principais temas presentes nas respostas; elaborada seqüencialmente até cobrir todas as respostas; 
6. a análise de cada resposta e a identificação dos temas presentes;

7. tabulação final e seleção de exemplos para ilustrar cada tema.

É importante lembrar na análise a ser mostrada, que as respostas estão sendo dadas no contexto da descrição de um programa, projeto ou atividade e não no contexto de uma investigação sobre inovação. O que talvez se possa argüir, é que no conjunto das 89 respostas, é possível que boa parte das versões intuitivas sobre inovação estejam presentes, e que os temas identificados sejam, provavelmente, aqueles encontrados ao se buscar "inovação em uso". Também é provável que na grande maioria de casos, a resposta acabe se transformando no produto de um processo de discussão ou, pelo menos, de troca de idéias sobre como preencher a ficha, de como responder às perguntas. É uma resposta que faz sentido para as pessoas presentes, ao versar sobre aquele programa, projeto ou atividade. Não se sabe quais seriam as razões dadas no caso de um outro programa, projeto ou atividade. Assim sendo, se os temas podem ser considerados como representativos do universo de falas sobre a inovação no âmbito das ações cotidianas, não se pode concluir que a frequiência do seu uso seria a mesma em outras circunstâncias.

\section{Principais temas presentes nas respostas}

Foram sete os principais temas identificados. Das 89 respostas, 66 foram classificadas em somente um ou outro desses temas específicos, e em 23 casos foi necessário juntar temas para fazer a classificação, porque a resposta tratou explicitamente de diversas noções sobre inovação. Na exposição a seguir, primeiro, serão discutidos os sete temas principais e sua distribuição. Depois, as várias respostas múltiplas.

\section{a) mudança de prioridades e inclusão passiva}

O primeiro tema se refere às ações em que há uma mudança de prioridades: levando serviços para grupos ou setores da população anteriormente excluídos, "humanizando" serviços existentes (tornando-os mais receptivos, cordiais e amigáveis) e reconhecendo necessidades. São ações concebidas a partir da organização prestadora de serviços e sem uma inclusão ativa do outro na discussão ou na direção dos serviços. Alguns exemplos:

"Ao pensarmos a situação do idoso em nossa sociedade não podemos nos furtar à análise da patente condição de exclusão social a que [ele] está submetido. O 'velho' em nossa sociedade foi relegado ao papel (...) portanto ao oferecermos 'ouvidos' às suas ansiedades e aflições (...) acreditamos estar fazendo, conjuntamente com eles, um movimento inverso..."

“A principal inovação (...) é o fato de que o programa entende e é concebido a partir das necessidades de cada comunidade, daí termos aberto o leque de modalidades para o buraco, o dominó e outras práticas de lazer que foram incorporadas ao programa, pois são tradicionais nas comunidades de baixa renda..."

"A maior inovação foi o aumento da segurança e a qualidade no atendimento às gestantes e recém-natos, através da humanização do atendimento, vinculação das gestantes aos serviços de saúde e monitoração constante dos agravos à saúde da grávida..."

"Mudar o enfoque da comunicação pública: a informação com fluxo regular, fácil acesso, interesse direto, com fins de cidadania e linguagem objetiva; um serviço prestado à cidade, uma estrutura e uma energia voltados à coletividade."

"A realidade do projeto é à vontade de ver a população carente, da periferia, tendo acesso a projeções de filmes de circuito, já que não tem condições de ter em casa um videocassete. Atrelados a esses filmes, vão-se introduzindo filmes documentais, educativos, e o vídeo-jornal, com informações da área cultural do município e questões importantes de educação e saúde." 
Esse tema foi um dos de menor freqüência nas respostas. Foi a base única da resposta de cinco dos responsáveis pelos programas, projetos e atividades, tendo sido incluído como parte de uma resposta múltipla em quatro outros.

\section{b) ações pró-ativas na busca de novas soluções para problemas existentes}

O segundo tema focaliza a discussão de soluções ou abordagens para problemas existentes e conhecidos. As soluções podem ser técnicas, administrativas ou organizacionais - por exemplo, envolvendo intersetorialidade - e tendem a ter um tom de pró-atividade, de estar se estendendo e indo ao encontro do outro. Aqui também há o início de uma discussão sobre "empoderamento" (empowerment), mas focalizando o sujeito individual, o cidadão, e não o coletivo. Alguns exemplos:

"O programa, além de contribuir com o aumento da produção de pescado nos açudes, procurou fomentar junto às associações, cooperativas e produtores rurais, a prática de piscicultura intensiva e superintensiva (...) com o sistema de cultivo race-way."

"Pela primeira vez em 23 anos de existência do Estado, o poder público assumiu essa nova função em um momento em que o Estado se encontrava em grandes dificuldades econômicas. A Instituição Comunitária de Crédito (...) é ação inovadora e um grande desafio especialmente pela abrangência (...) estadual e não municipal."

"Não havia agregação nenhuma no passado. Os castanheiros simplesmente colhiam e vendiam. Hoje colhem com tecnologia, pois foram construídos sistemas de paióis tipo palafita (...), também implantamos um sistema de secagem (...) introduzimos um sistema de choque térmico (...) também o sistema de embalagem hoje está inovando, com um sistema a vácuo..."

"A discussão sobre as análises dos óbitos com gestor e equipe de saúde constitui ponto inovador, pois acreditamos que os resultados obtidos nas análises dos óbitos representam a primeira contribuição para a reorganização da assistência à saúde..."

"A inovação consiste no encontro da alternativa que possibilitou atender, com recursos energéticos, as comunidades até então privadas do uso da eletricidade pela inviabilidade econômica de fornecimento tradicional..."

"Seu ponto mais inovador encontra-se na independência e autonomia da ouvidoria em relação aos poderes constituídos (Executivo, Legislativo e Judiciário) garantidos pela lei de constituição e pelo processo de funcionamento. A forma de eleição do ouvidor também é outra inovação, uma vez que procura representar o pluralismo da sociedade..."

"A participação da família na construção do projeto de vida pessoal do jovem, que permite a conquista de sua cidadania, assegura seus direitos fundamentais e acompanha, incentiva e apoia o cumprimento da medida judicial, o envolvimento da comunidade e a inclusão de advogados...”

"Criamos a figura do Agente de Educação (fiscal, conselheiro e principalmente educador) que veio estreitar os laços entre a família e a escola, tão difíceis em comunidades como a nossa. Os trabalhos desenvolvidos têm o acompanhamento do Conselho Tutelar, minimizando a evasão escolar e as altas taxas de repetência."

O tema $b$ foi o mais encontrado entre as respostas, tendo sido a base única da resposta de 38 dos programas, projetos e atividades, fazendo parte da resposta múltipla de mais 14. No total, as respostas dos 52 responsáveis $(58 \%)$ foram, total ou parcialmente, classificadas nessa categoria.

\section{c) transferência de tecnologia (técnica ou administrativa) de uma área para outra}

Esse tema pode ser encontrado nos critérios de inscrição (repetição da experiência por outros ou transferência para outros), mas parece ser o menos usado pelos semifinalistas ao descrever suas atividades. $\mathrm{O}$ tema $c$ foi somente encontrado em três casos; e em todos fez parte de uma resposta múltipla. Aqui estão (grifo nosso): 
"O programa inovou ao se desafiar a transpor para uma esfera mais ampla de trabalho (município e desenvolvimento local) uma concepção teórico-metodológica (...) capaz de gerar organizações protagonistas, empreendimentos auto-gestionários e cidadãos críticos.”

"Envolvimento das comunidades na elaboração e implantação dos projetos; conservação do meio ambiente em projetos produtivos; aplicação de tecnologia de manejo de água, de solo e de cultivo de frutos e hortaliças, de forma sustentável, entre os pequenos produtores do semi-árido do Ceará.”

"O projeto foi construído com base em relações muito mais democráticas entre serviços, universidade e comunidade, ao criar uma dinâmica mais horizontal entre os parceiros, possibilitando que muitos atores se tornassem participantes ativos; ação articulada entre universidade, serviços e comunidade; construção de parceria, co-gestão e transferências de tecnologias e saberes; empowerment da comunidade."

Nos três exemplos, a questão da transferência de tecnologia ocupa um lugar complementar na resposta, acompanhando outras razões vistas como mais importantes.

d) inclusão ativa e coletiva, abrangendo participação e co-gestão na busca de soluções e no monitoramento de ações

O tema $d$ teve uma presença sólida entre as respostas, sendo a base única de nove respostas e fazendo parte de mais oito, ou seja, 17 (19\%) ao todo. Alguns exemplos:

“O PAE é uma alternativa inovadora na sua forma de levar às populações carentes a questão da geração de ocupação e renda. A metodologia utilizada (...) envolve a comunidade na discussão, no desenvolvimento e na implantação de alternativas (...) as decisões nascem de baixo para cima (...) o processo rompe com o assistencialismo..."

"Participação dos agricultores e entidades na construção do processo de feiras juntamente com o poder público."

"Gestão integrada, delimitação das áreas impróprias à ocupação, com o desenvolvimento da fiscalização urbana e ambiental preventiva, em parceria com a comunidade local; definição de uso ambiental para as áreas impróprias; enfrentamento e soluções criativas; aprofundamento do processo de participação."

"O programa é voltado para uma discussão horizontalizada das demandas de segurança, bem como para atender as demandas da comunidade apresentadas através das comissões locais.”

"O envolvimento da comunidade com a equipe multiprofissional (integra vários profissionais) $e$ várias ações in loco garantem o acesso da população à saúde preventiva e curativa, promovendo o resgate da cidadania, a participação e o controle social."

"Recifes artificiais de pneus, debates com a comunidade sobre a implantação de novos pesqueiros, discutindo estratégias e a remuneração de pessoal envolvido."

\section{e) mudança no enfoque de como pensar a ação}

Nesse tema são incluídos os comentários sobre a mudança significativa de enfoque, a ampliação de maneiras de pensar - explicitamente interdisciplinar, com o envolvimento de múltiplos atores - e a aplicação de temas norteadores como, por exemplo, enfoque sobre desenvolvimento integrado, ou sobre a sustentabilidade ambiental. Essa foi a segunda categoria mais encontrada, com 19 respostas (21\%), sendo a base única de 11 respostas, formando parte de mais oito respostas multitemáticas.

"O plano de desenvolvimento pensado a partir do município (rural/urbano, empresas/cooperativas etc.) significa uma mudança, em primeiro lugar, da cultura de gestão 
municipal (...) em segundo lugar, integra economia solidária, agricultura, indústria e mercado numa visão mais ampla."

"Apenas o governo (...) incorporou esse desafio em seu programa de governo, o recorte de gênero, reconhecendo os direitos das mulheres, inclusive o de ter uma vida sem violência. A implantação de políticas públicas com recorte de gênero, um trabalho conjunto dos movimentos autônomos, conselhos, prefeituras..."

"À medida que o projeto foi retomado e evoluiu, notou-se a necessidade de ampliar a discussão sobre DST/Aids e os aspectos em torno desses temas para outros atores dentro da realidade prisional (...) desfazendo preconceitos e desconstruindo estereótipos...”

“O programa teve como inovação quanto às práticas anteriores, a abrangência da clientela: atende desde a educação infantil até o ensino superior, assim como o município, envolvimento com parceiros, comunidade e unificação de redes de ensino."

"A grande inovação obtida pelo programa (...) foi modificar radicalmente a maneira de avaliar e conduzir o processo de adequação sanitária nos estabelecimentos de saúde. Adotou-se uma nova abordagem técnica e profissional, com enfoque no grau de risco (ao invés de [uma abordagem] policialesca e de desconfiança) através de pacto 'consensado'."

\section{f) articulação com outros e novos arranjos institucionais}

O tema das parcerias, vínculos e alianças tem sido constante nas discussões sobre os projetos e programas apresentados para o Programa Gestão Pública e Cidadania, e é também uma característica muito frequiente nas inscrições. Entretanto, quando esse tópico está presente como tema de inovação, junto com as novas formas de criar e pensar sobre arranjos institucionais, é quase sempre como parte de uma resposta maior, ou multitemática. Isso sugere, talvez, que as articulações e arranjos institucionais são considerados muito mais como parte de uma solução do que a solução em si; parte da pragmática da ação e não a inovação em si. Aqui estão as duas únicas respostas monotemáticas sobre esse tema:

"É um projeto de parcerias que envolvem órgãos oficiais, ONGs, empresa privada e comunidade indígena (...). A prática utilizada no desenvolvimento do trabalho é centrada na democracia e na coletividade...”

"Consolidação de projetos em parceria com poder público e ONGs, produzindo um modelo de gestão em que a palavra de ordem se assenta nas parcerias; inserir a comunidade de uma forma plena implicava também responsabilidades na solução dos problemas de manutenção, desenvolvimento e gestão."

\section{g) a primeira vez na área, o primeiro de seu tipo, pioneiro}

Essa visão sobre inovação reflete o seu uso no cotidiano como algo novo e, portanto, de alguma forma pioneiro. Foram cinco as respostas que podem ser classificadas assim, mas em quatro casos tratou-se de parte de uma resposta multitemática, adicionando algo a mais às outras razões apresentadas. Em somente um caso o tema foi usado como resposta singular:

"Assessoria in loco aos municípios, detectando as necessidades e esclarecendo dúvidas sobre o processo de implantação de instrumentos de gestão. O projeto é inovador justamente por não existir em nível nacional nenhuma proposta semelhante à realizada por esta superintendência." 
h) as respostas múltiplas ou multitemáticas

Considerando todas as fichas analisadas, é a categoria $b$ - "ações pró-ativas na busca de novas soluções para problemas existentes" que emerge como sendo mais presente, com 58\% das respostas. Em segundo lugar vêm as categorias $e$ - "mudança no enfoque de como pensar ação" e $d$ - "inclusão ativa e coletiva, abrangendo participação e co-gestão na busca de soluções e no monitoramento de ações", com $21 \%$ e $19 \%$, respectivamente, seguidas por $f$-"articulação com outros e novos arranjos institucionais" e $a$ - "mudança de prioridades e inclusão passiva", com $11 \%$ e $10 \%$. Os menos freqüentes foram $g$ - "a primeira vez na área, o primeiro de seu tipo, pioneiro" e $c$ - "transferência de tecnologia (técnica ou administrativa) de uma área para uma outra", com $6 \%$ e $3 \%$, respectivamente.

Em $25 \%$ das respostas à pergunta "em que aspectos seu programa, projeto ou atividade inovou em relação a práticas anteriores?", a análise identificou a presença de diversos temas e dois destes - "novos arranjos" e "pioneirismo" - já foram mencionados nesse contexto, sendo usados muito mais como parte de uma resposta do que como argumento isolado. Aqui estão alguns exemplos:

“Inovou, pois as mulheres e as crianças - vitimas da violência - não sentem que estão 'presas'. $O$ abrigo, hoje, é a sua casa, seu refúgio, o espaço que irá garantir sua formação para a vida e o mercado de trabalho. Trabalhamos com uma rede de apoio e temos como molas-mestras as parcerias.”

"A intervenção exigiu aprofundamento das articulações com o Ministério Público, órgãos ambientais e comunidade. Foi implementado o Programa Bairro Ecológico, através do qual os moradores executam calçadas, preservando a permeabilidade com grama, e a arborização com espécimes nativos da Mata Atlântica, e a prefeitura executa o pavimento drenante."

"Três fatores: o protagonismo juvenil usando temas transversais (cidadania, gênero); interface mais intersetorialidade com as demais secretarias; parcerias com os movimentos populares.”

"Ao contrário de outras iniciativas articuladas no campo da geração de renda, o projeto vai além das condições materiais: concebe o seu público-alvo em situação de exclusão material mas também social, cultural e política. Propõe uma metodologia com estratégias que buscam resgatar o senso crítico e criativo (...), articulação de parcerias com a sociedade civil."

"A inovação vem do modelo misto governamental e sociedade civil, pioneiro no país. As tradicionais agências de desenvolvimento não envolvem a sociedade civil (...). A agência traz a comunidade em sua modelagem...”

"Abre novas possibilidades econômicas nas áreas de preservação, ajudando a criar uma vida digna, utilizando conhecimento próprio; também inova ao conseguir a primeira licença de manejo para uma espécie não madeirável da Mata Atlântica...”

"O plano de manejo não está sendo feito em gabinete (...) os grupos de interessados podem realmente interferir no processo de gestão, decisões são tomadas por consenso (...) o manejo participativo é pioneiro no Brasil."

Um outro grupo de respostas múltiplas juntou temas presentes na categoria $a$ - "mudança de prioridades e inclusão passiva", e na categoria $b$ - "ações pró-ativas na busca de novas soluções para problemas existentes": 
"Criação de um sistema (usando o telefone) que responde prontamente a uma vasta demanda dos idosos, permitindo ao poder publico uma leitura dinâmica dessa demanda, contribuiu para dar visibilidade à questão do idoso na cidade, tornou-se uma referência cidadã - é considerado pelos idosos como um pronto-socorro sigiloso.”

“O programa (...) inovou o conceito de produção de eventos culturais, porque viabiliza realmente o acesso para todas as camadas sociais, em especial os carentes (usando transporte e gratuidade) ao mesmo tempo em que associa essa 'oferta' de produção e acesso aos bens culturais com experiência de solidariedade."

"Priorização da população de baixa renda, integralidade e multissetorialidade constituem o fator inovador; ações de infra-estrutura física, comunitária, de geração de emprego e renda e educativa concentradas numa mesma área de atuação.”

“A proposta de fortalecimento da unidade familiar, envolvendo os diversos serviços ofertados pelas políticas básicas setoriais, proporcionando-lhes o resgate de sua auto-estima. A garantia de direitos que a sociedade presta, por meio do Estado, a essas famílias socialmente excluídas, evita sua exclusão social futura. Essa é a inovação.”

Outras, ainda, incluíram temas presentes em três categorias. Por exemplo:

“Envolvimento das comunidades na elaboração e implantação dos projetos; conservação do meio ambiente em projetos produtivos; aplicação de tecnologia de manejo de água, de solo e de cultivos de frutos e hortaliças de forma sustentável entre os pequenos produtores."

"A principal inovação deve ser atribuída ao processo de criação da proposta, que se deu de forma endógena, o que propiciou uma gestão democrática com a participação ampla e irrestrita de seus usuários, através de uma parceria também inovadora que envolve o poder público, ONGs e sociedade civil. Outro aspecto foi a inovação na forma de gerenciamento de carteira e na metodologia de concessão e acompanhamento do crédito rural, possibilitando um acesso ágil e descomplicado.”

“O projeto foi construído com base em relações muito mais democráticas entre serviços, universidade e comunidade. Ao criar uma dinâmica mais horizontal entre os parceiros possibilitou que muitos atores se tornassem participantes ativos; ação articulada entre universidade, serviços e a comunidade; construção de parceria, co-gestão e transferências de tecnologias e saberes; empowerment da comunidade."

\section{Experiências inovadoras versus melhores práticas}

Se "inovação", voltando ao seu uso diário e cotidiano, é normalmente entendida como algo novo em relação ao anterior, nas respostas parece que as pessoas responsáveis pelos programas, projetos e atividades inscritos no ciclo de premiação do Programa Gestão Pública e Cidadania têm muito pouca dificuldade em reconhecer onde as mudanças estão. As respostas são claras e variadas; as razões apresentadas mudam de um contexto para o outro - às vezes, mais extensas e mais complexas; às vezes, mais diretas e mais simples -, mas sempre à altura 
da pergunta. A pergunta, por sua vez, é compreendida e respondida dentro de uma postura dialógica. Por isso, a variedade de respostas é importante.

Parece que, diferente de uma pergunta que "sugere" uma resposta "correta", a pergunta "em que aspectos seu programa, projeto ou atividade inovou em relação a práticas anteriores?" não leva à descrição de uma inovação "nota 10", mas daquilo que é inovador no programa, projeto ou prática. O resultado é não somente a variedade de respostas apresentadas e as diferentes categorias encontradas, mas a quase ausência de uma resposta construída "para fazer bonito". Os responsáveis pelas inscrições estão preparados para ter suas ações avaliadas em relação àquilo que são - práticas que inovam em relação às anteriores -, e não buscam descrever seus trabalhos numa linguagem de melhores práticas.

Quais seriam os resultados e respostas a uma questão do tipo: "justifique por que seu programa, projeto ou prática deve ser considerado uma das melhores práticas"? Sem dúvida, cada um buscaria mostrar seu programa ou projeto às melhores luzes dos temas do momento, no desenvolvimento e na gestão local, usando, por exemplo, termos como empreendedorismo, parcerias, participação popular e transferência de tecnologia. Afinal, "melhor" quer dizer "em relação ao outro" e em relação a algum "padrão de excelência".

Ao contrário, parece que no Programa Gestão Pública e Cidadania, a briga não é com o outro - uma certa rivalidade, talvez - mas com o anterior: o importante é alterar aquilo que lá está. Ainda estamos, se a distribuição de respostas pode ser considerada como representativa do pragmatismo subnacional, numa situação onde o protagonismo mais coletivo, a construção de novos desenhos institucionais, o repensar de abordagens e a co-gestão da esfera pública ainda não encontraram tanto espaço quanto a simples inversão de prioridades, a inclusão individual e a resolução técnica e prática de problemas. Dar atenção aos que precisam, reorientar o orçamento público e utilizar as competências presentes pode não ser uma melhor prática... mas não é nada mal para a construção da democracia. 


\section{Referências bibliográficas}

CARVALHO, J. M de. Cidadania no Brasil. Rio de Janeiro: Civilização Brasileira, 2001.

CORNWALL, A. Beneficiary, consumer, citizen: perspectives on participation for poverty reduction, Sida Studies, Stockholm, n.2, 2000.

ESTEVA,G.; PRAKASH, M. S. Grassroots Post-modernism: remaking the soil of cultures. New York: Zed Books, 1998.

FARAH, M. F. S. Gênero e políticas públicas na esfera local de governo. Organizações e Sociedade. v.6,n.14, p.65- 104, 1999.

Parcerias, novos arranjos institucionais e políticas públicas no nível local de governo. Revista de Administração Pública, v.35,n.1, p.119-114, 2001.

; SPINK, P. K. The Brazilian Public Management and Citizenship Program: an overview. Cadernos de Gestão Pública e Cidadania. Centro de Administração Pública e Governo - Eaesp/FGV, v.25, 2003.

GARFINKEL, H. Studies in ethnomethodology. New York: Prentice Hall, 1967.

GEERTZ. C. Local knowledge. New York: Basic Books, 1983.

MARSHALL, T. A. Cidadania, classe social e status. Rio de Janeiro: Zahar 1967.

OLSSON, J.; WOHLGEMUTH, L. (Orgs). Dialogue in pursuit of development. Stockholm: Almqvist \& Wiksell International, 2003.

SPINK, P. K. The rights approach to public management: experiences from Brazil. Revista de Administração de Empresas, v.40, n.3, p.45$65,2000$.

Avaliação democrática: propostas e práticas. Fundamentos de Avaliação. Coleção Abia - Associação Brasileira Interdisciplinar de Aids, Río de Janeiro, n.3, 2001. 